\title{
THE INFLUENCE OF DEFORMATION UNDER TENSION ON HARDNESS, FRICTION AND WEAR IN SELECTED THERMOPLASTICS
}

\author{
M. Kujawa*
}

\begin{abstract}
Due to a few important advantages, plastics encourage scientists and engineers to apply them in more and more sophisticated components (e. g. fluid power components or sliding elements). A vast majority of components are deformed after assembly. The aim of this study is to determine the influence of deformation under tension on hardness, friction and wear of PA6, PTFE and PE-HD. In terms of all examined plastics, reduction of hardness is observed (up to 38\%) for deformed specimens. Moreover, this phenomenon is observed even during the initial stage of deformation (up to $\epsilon=2,5 \%$ for PE-HD and PA6; $\epsilon=1,25 \%$ for PTFE). Deformation (tension) affected wear in terms of all examined thermoplastics. Wear gets larger as a specimen is more deformed. In terms of coefficient of friction only PA6 appeared to be sensitive to deformation (value changed up to 10\%). Deformation affects properties of PA6, PTFE and $P E-H D$. This fact ought to be consider during designing components made of this thermoplastics and analysing material behaviour and failure reasons. Moreover, changes occur during the initial stage of deformation (up to $\epsilon=2,5 \%$ for PE-HD and PA6; $\epsilon=1,25 \%$ for PTFE). As it appears, deformation through tension causes increase in wear.
\end{abstract}

\section{Keywords: PA6, PTFE, PE-HD, deformation}

\section{Introduction}

Nowadays a lot of mechanical components are made of plastics. Plastics are mainly used as a material for not high loaded parts such as: housings, grips, buttons etc. However, plastics have a few important advantages that encourage designers to applicate them in more and more sophisticated components. For instance, in comparison with metals, plastics required less energy during processing, they might be fast shaped using injection molding and their density is lower. For instance, application of plastics instead of metals is a currently observed tendency in the making of fluid power elements like pumps, valves and hydraulic cylinders (Stryczek et al., 2017). Moreover, due to impressive anti-corrosion properties PTFE is used as a lining layer in tubes. In terms of sliding elements, polymers are used mainly because of their ability to work without grease. Components after assembly are compressed or deformed under tension. For instance, bushing pressed into a hole is compressed and seal is deformed under tension (Fig. 1).

a)
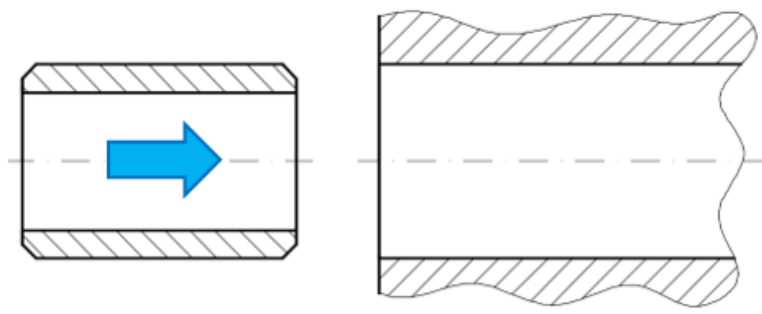

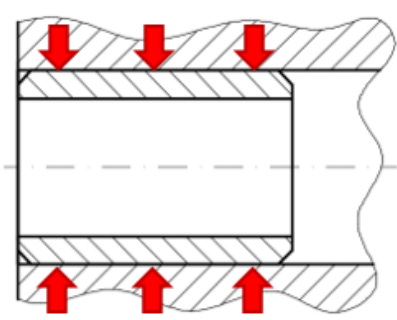

b)

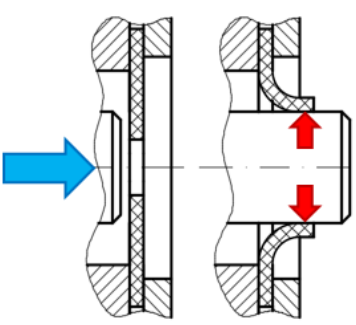

Fig. 1: Examples of components deformed after assembly): a) Bushing pressed into hole is compressed; b) Seal mounted on shaft placed inside a hole is deformed 
Moreover, scientist and engineers are constantly trying to find new ways to improve polymers properties (Niemiec, 2017; Friedrich et al., 2011). Deformation under tension may be a chance to achieve this goal. There is a lack of information about influence of deformation under tension on mechanical properties of polymers. Papers describe only the influence of big strains $(\epsilon>100 \%)$ as there is molecular orientation in polymers (Liu et al., 2005). Research conducted for metals shows that even small strains affect tribological properties of material (Buciumeanu et al., 2009).

The author of this publication conducted a few preliminary research about the influence of strain on coefficient of friction and hardness in polymers (Kujawa et al., 2017). This research is focused on small strain (up to $1 \div 2,5 \%$ ) since these values are permissible in mechanical components, and it appears that they affect hardness. Moreover, in this research the author points out increased wear of deformed thermoplastics.

\section{Materials and methods}

Two states of polymer materials were investigated during the research: undeformed and deformed. Microhardness the friction coefficient and wear are tested. Specimens were deformed under tension at room temperature $\mathrm{T}_{0}=22{ }^{\circ} \mathrm{C}$ using a specially designed holder. This holder was assembled into the pinon-plate tribotester and micro hardness tester (Fig. 2), therefore, the deformation of the specimen was maintained during the examinations. Without the holder, a specimen would return to its original shape due to rheological phenomena.

The specimens were cut out of sheets. They were made of three polymers: highdensity polyethylene (PE-HD), polytetrafluoroethylene (PTFE), and polyamide 6 (PA6). Their shape was similar to a standard tensile-test specimen. They were $2 \mathrm{~mm}$ in thickness and $5 \mathrm{~mm}$ in the width of the 'reduced' section. There were grip sections at the ends to prevent slipping out of grips.

a)

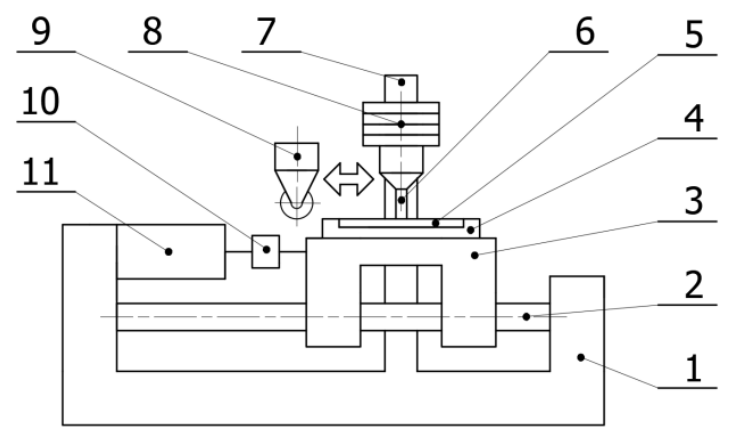

b)

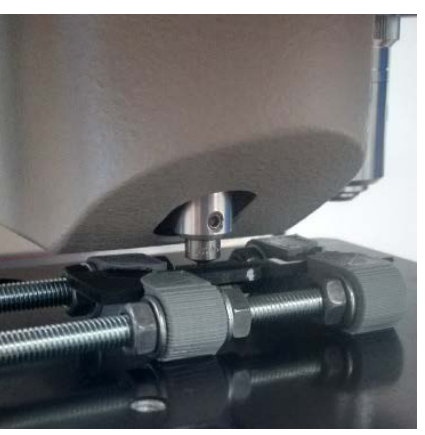

C)

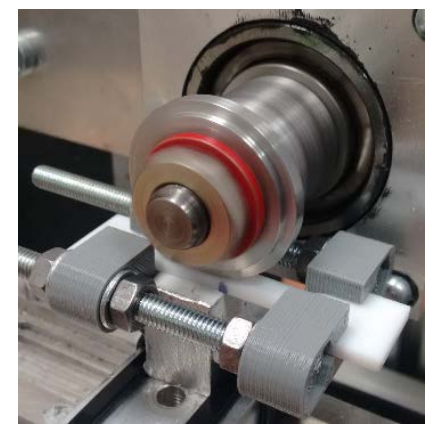

Fig. 2: a) The scheme of the pin-on-plate tribotester used in the current research (1- the base, 2 - the way, 3 - the bed, 4 - a specimen, 5 - the specimen holder, 6 - a counter specimen, 7 - the way of counter specimen fastening, 8 - weight plates, 9 - roller driven by stepper motor that may be assembled as an alternative for (6) to perform wear test, 10 - the friction force sensor, 11 - the electric actuator); b) Specimen in holder during hardness test; b) Specimen in holder during wear test

The Knopp hardness test was performed using Schimadzu HMV micro hardness tester. Four measurements were conducted and then mean and expanded uncertainties were calculated. A $980.7 \mathrm{mN}$ load was applied during 5 seconds.

Measurements of the friction coefficient were carried out for reciprocating motion using a pin-on-plate tribotester described in the paper (Kowalewski et al., 2007). Figure 2a shows the scheme of the apparatus. The investigated tribological pair consisted of polymer plate and steel pin with a diameter of $3 \mathrm{~mm}$. The surface roughness $\mathrm{Ra}$ of the counter specimen was $(1.14 \pm 0.02) \mu \mathrm{m}$. Contact pressure was $3.0 \mathrm{MPa}$. The measurements of hardness and the coefficient of friction were conducted directly after obtaining desired strains.

Wear test was performed using a roller driven by a stepper motor. The roller (30 mm diameter and $3 \mathrm{~mm}$ thick) was made of steel and its surface roughness Ra was $(1.01 \pm 0.13) \mu \mathrm{m}$. Since examined materials have very different resistance to wear, wear tests parameters were diversified. In terms of PTFE, sliding 
velocity was $0,75 \mathrm{~m} / \mathrm{s}$, sliding distance was $500 \mathrm{~m}$ and force that pressed thr roller into specimen was $20 \mathrm{~N}$. In terms of PE-HD, sliding velocity was $0.5 \mathrm{~m} / \mathrm{s}$, sliding distance was $4000 \mathrm{~m}$ and force that pressed the roller into specimen was $100 \mathrm{~N}$. In terms of PA6, sliding velocity was $0.5 \mathrm{~m} / \mathrm{s}$, sliding distance was $1000 \mathrm{~m}$ and force that pressed the roller into specimen was $30 \mathrm{~N}$. After a wear test scar width was mesured and this value was used to calculate wear groove deph.

\section{Results and discussion}

In terms of all examined plastics reduction of hardness is observed for deformed specimens (Fig. 3).

a)

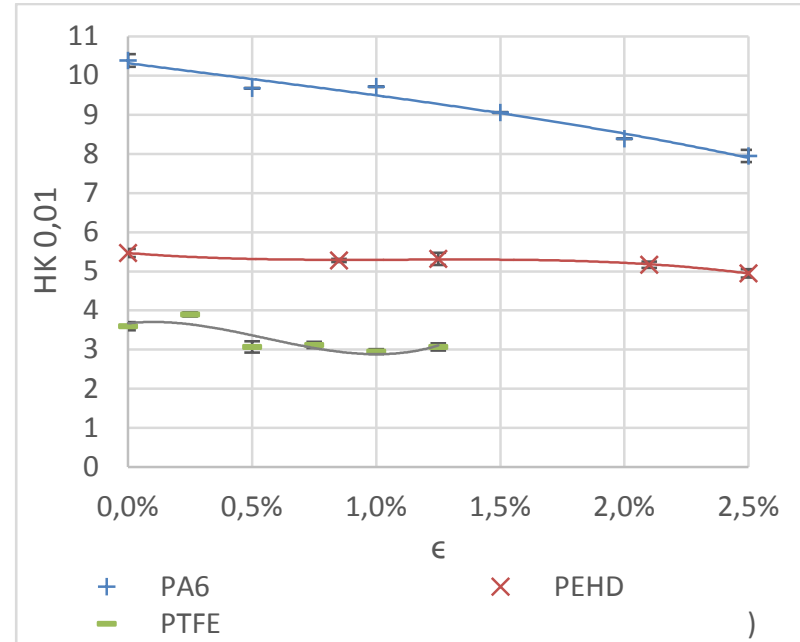

b)

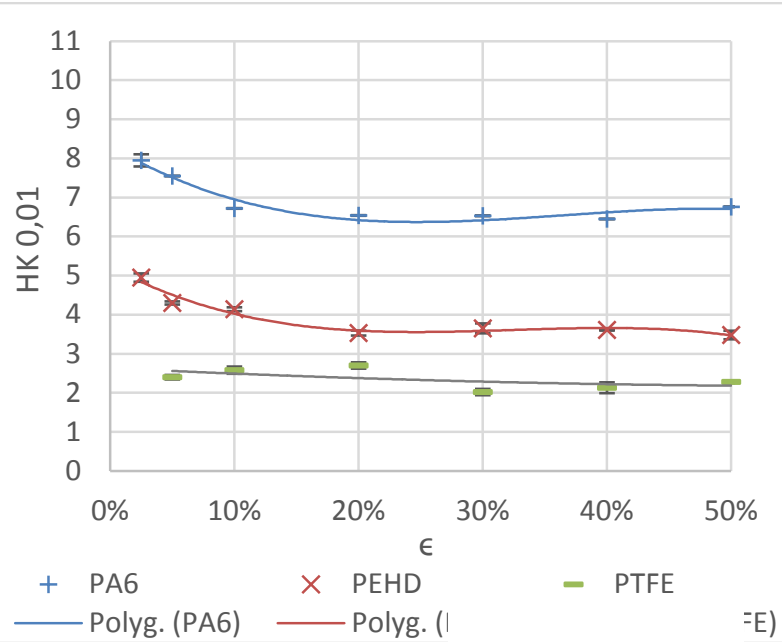

Fig. 3: Hardness of examined thermoplastics, the trend line and confidence intervals $(1-\alpha=0,95)$ : a) Initial stage of deformation; b) Higher strain

In terms of coefficient of friction only one thermoplastic appeared to be sensitive to deformation (Fig. 4a). Deformation affected wear in terms of all examined thermoplastics (Fig. 4b).

a)

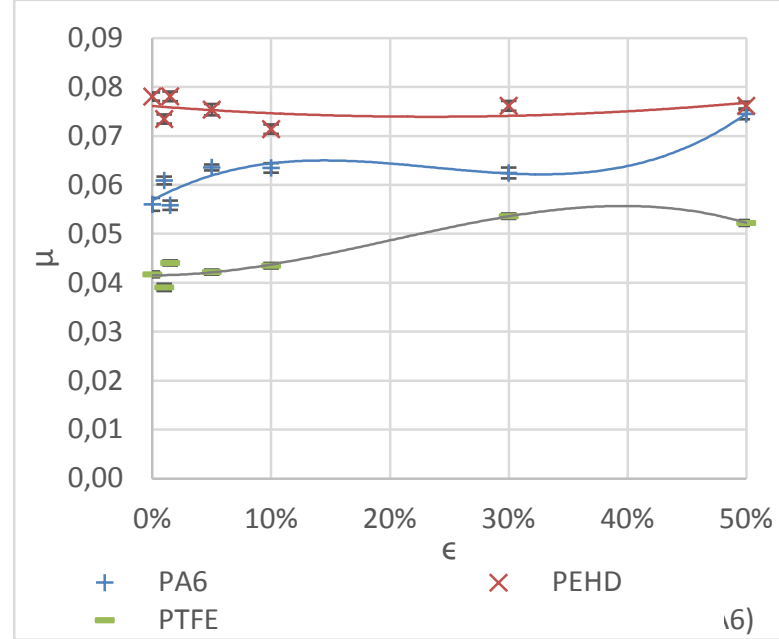

b)

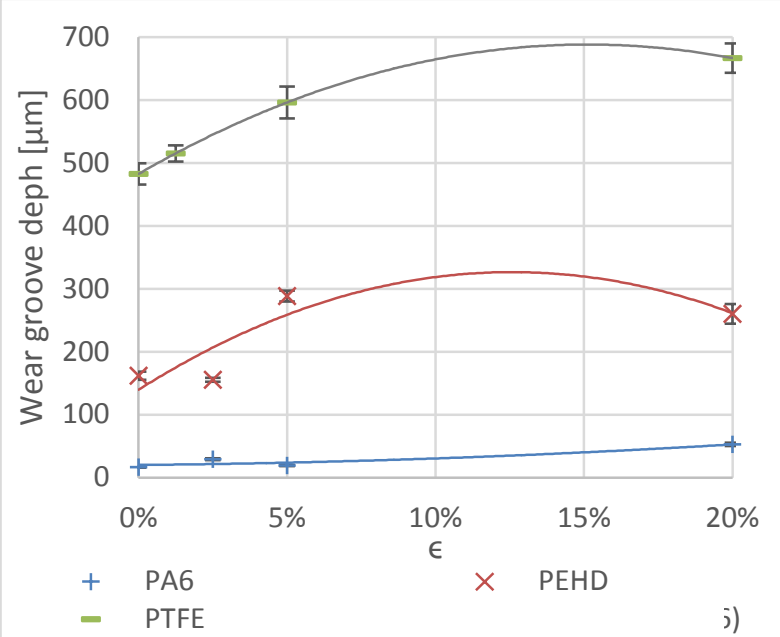

Fig. 4: a) Friction coefficient, the trend line and confidence intervals (1- $\alpha=0,95)$ for the pair thermoplastic - steel (A1) in case of not deformed and deformed polymer (sliding velocity $v=5 \mathrm{~mm} / \mathrm{s}$, contact pressure $p=3 \mathrm{MPa}$ ); $b$ ) Wear groove depth, the trend line and confidence intervals $(1-\alpha=0,95)$ - wear test parameters described in the text

Reduction of hardness is observed even during the initial stage of deformation (up to $\epsilon=2,5 \%$ for PE-HD and PA6; $\epsilon=1,25 \%$ for PTFE). After reaching approximately $10 \%$, strain hardness value hoovers. When strain reached approximately 2,5\%, hardness decreased at almost 25\% (PA6) and 27\% (PE-HD). As far as 
PTFE is concerned, when strain reached $1,25 \%$, hardness decreased at about $14 \%$. The maximal reduction of hardness is 38\% (PA6) and 36\% (PE HD, PTFE).

As for PA6, coefficient of friction varies up to $10 \%$. In terms of PTFE, change in the value of coefficient of friction was observed at higher strains $(\epsilon=30 \%$ and more). At $30 \%$ and $50 \%$ strain coefficient of friction was approximately $28 \%$ larger than for not deformed specimen. The most significant change in the coefficient of friction value was observed during PA6 examination. At 50\% strain coefficient of friction was approximately 33\% larger than for not deformed specimen. PE-HD appeared to be insensitive to deformation (tension). Coefficient of friction varied only slightly. Wear gets larger as specimen is more deformed. In terms of PTFE and PA6, increased wear is observed even during the initial stage of deformation ( $\epsilon=1 \%$ for PTFE and $\epsilon=3 \%$ for PA6).

During deformation structural changes occur (White J. L. et al, 2006). Moreover, the author of this publication conducted a research that proved that deformation affects the Surface Free Energy (Kujawa et al. 2017). The SFE is higher at higher strain. The SFE is connected with adhesion abilities of material. Adhesive wear is a characteristic type of wear of polymer materials. It appears that structural changes cause lowering hardness, and SFE changes cause increase of wear.

\section{Conclusions}

Deformation (tension) affects properties of PA6, PTFE and PE-HD. This fact ought to be consider during designing components made of this thermoplastics and analysation of material behaviour and failure reasons.

Hardness lowers with deformation (tension). It occurs mainly during the initial stage of deformation (up to $\epsilon=2,5 \%$ for PE-HD and PA6; $\epsilon=1,25 \%$ for PTFE). Strains, up to values listed above, are permissible during designing mechanical elements. Engineers ought to consider this fact since hardness might be a crucial parameter of material in some instances.

The vast majority of attempts to improve plastics' tribological properties are focused on reducing wear and coefficient of friction. Deformation through tension causes increase in wear. Coefficient of friction increases with strain, however, changes are not significant. Therefore, tension is not promising way to process thermoplastics.

\section{References}

Buciumeanu M., Crudub I., Palaghianb L., Mirandaab A.S., Silvaa F.S. (2009) Influence of an additional elastic stress on dry wear behaviour in reciprocating tests. Tribology International, 42, 7, pp. 1101-1107.

Friedrich K., Chang L., Haupert F. (2011) Current and Future Applications of Polymer Composites in the Field of Tribology, [in:] Nicolais L., Meo M., Milella E. (eds) Composite Materials. Springer, pp. 129-136.

Kowalewski P., Wieleba W., Leśniewski T. (2007) Tribological test rig for cyclic rolling and sliding contacts. Tribologia, 38, 2, 303-311.

Kujawa M., Paszkowski M., Wróblewski R. (2017) The influence of deformation on the surface free energy of selected polymers. 7th International Colloids Conference, Sitges-Barcelona.

Kujawa M., Wieleba W. (2017) The influence of a constant state of deformation on the friction coefficient in selected thermoplastics (polymer-steel pair). Tribologia., 48, 4, pp. 39-45.

Liu X.-X., Li T.-S., Liu X.-J., Lv R.-G. (2005) Study on Tribological Properties of Polytetrafluoroethylene Drawn Uniaxially at Different Temperature. Macromolecular Materials and Engineering, 290, 3, pp. 172-178.

Niemiec A. (2017) The analysis of the influence of gamma irriadiated polysulfones on the static friction coefficient. Tribologia, 48, 4, pp. 65-70.

Stryczek J., Banaś M., Krawczyk J., Marciniak L., Stryczek P. (2017) The fluid power elements and systems made of plastics. Procedia Engineering, 176, s. 600-609.

White J. L., Shan H. (2007) Deformation-Induced Structural Changes in Crystalline Polyolefins. Polymer-Plastics Technology and Engineering, 45, 3, pp. 317-328. 